\title{
Report on Laboratory Tests of Drying and Re-Wetting of Intact Rocks
}

Jeffery J. Roberts

RECEIVED

APR 081396

Wunan Lin

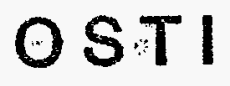

March 1996

This is an informal report intended primarily for internal or limited external distribution. The opinions and conclusions stated are those of the author and may or may not be those of the Laboratory.

Work performed under the auspices of the U.S. Department of Energy by the Lawrence Livermore National Laboratory under Contract W-7405-Eng-48. 


\section{DISCLAIMER}

This document was prepared as an account of work sponsored by an agency of the United States Government. Neither the United States Government nor the University of California nor any of their employees, makes any warranty, express or implied, or assumes any legal liability or responsibility for the accuracy, completeness, or usefulness of any information, apparatus, product, or process disclosed, or represents that its use would not infringe privately owned rights. Reference herein to any specific commercial products, process, or service by trade name, trademark, manufacturer, or otherwise, does not necessarily constitute or imply its endorsement, recommendation, or favoring by the United States Government or the University of California. The views and opinions of authors expressed herein do not necessarily state or reflect those of the United States Government or the University of California, and shall not be used for advertising or product endorsement purposes.

This report has been reproduced directly from the best available copy.

Available to DOE and DOE contractors from the Office of Scientific and Technical Information

P.O. Box 62, O2k Ridge, TN 37831

Prices 2vailable from (615) 576-8401, FTS 626-8401

Available to the public from the

National Technical Information Service

US. Department of Commerce

5285 Port Royal Rd,

Springfield, VA 22161 


\section{DISCLAIMER}

Portions of this document may be illegible in electronic image products. Images are produced from the best available original document. 


\section{Milestone Report MOL120 \\ Report on Laboratory Tests of Drying and Re-wetting of Intact Rocks \\ Jeffery J. Roberts and Wunan Lin \\ Lawrence Livermore National Laboratory}

\section{Introduction}

This report is an update on progress made during FY1995 on hydrological property measurements performed in the laboratory. The report contains descriptions of experimental designs and procedures, data, observations, preliminary analyses, and future work. The primary focus of this report is the measurement of moisture retention curves of tuff as a function of temperature for both drying and re-wetting conditions. This work is a continuation of work described in MOL80 (UCRL-ID-119033), Hydrological Property Measurements of Topopah Spring Tuff (Roberts and Lin, 1995).

Knowledge of unsaturated transport properties is critical for understanding the movement of water through the unsaturated zone. Evaluation of the performance of a potential nuclear waste repository also depends on these properties. Moisture retention data are important input for models of moisture movement in unsaturated porous media. Also important is the effect of sample history on the moisture retention curves, whether or not a complete saturation cycle at elevated temperature affects the moisture retention curve at subsequent lower temperature cycles. This report addresses initial observations regarding this aspect of the research.

\section{Experimental Procedure}

Sample Description and Preparation. Samples from the Large Block Test, Fran Ridge, NTS (LBT) and from borehole USW-G4 were prepared in a similar manner. The LBT samples are discussed below. Twelve samples were prepared from borehole USW-G4, sample ID 17350.3, $1147 \mathrm{ft}$ depth. The samples were subcored to a diameter of $19.1 \mathrm{~mm}$ and cut into disks approximately $2.5 \mathrm{~mm}$ thick. Samples with obvious large cavities and inhomogeneous inclusions 
were avoided. The average porosity of the twelve samples is $11.1 \pm 1.7 \%$ and was determined by subtracting the dry density from the saturated density and dividing by the water density.

Calculation of matric potential. The matric potential is the pressure potential that arises from the interaction of water with a solid matrix (Marshall and Holmes, 1992). In tuff we assume that the suction potential is equal to the matric potential. Matric potential is defined by Kelvin's Law as

$$
\psi=\beta \mathrm{R} \mathrm{T} \ln \left(\mathrm{e} / \mathrm{e}_{0}\right) / \mathrm{M}
$$

where $\psi$ is the matric potential in MPa, $\beta$ is the density of water at the temperature of interest in $\mathrm{g} / \mathrm{cm}^{3}, \mathrm{R}$ is the universal gas constant $(8.314 \mathrm{~J} / \mathrm{Kmol}), \mathrm{T}$ is temperature in $\mathrm{K}, \mathrm{e} / \mathrm{e}_{0}$ is the relative humidity, and $M$ is the molecular weight of water $(18 \mathrm{~g} / \mathrm{mole})$.

To determine the moisture retention curve, samples were placed in the humidity chamber at a specific temperature and $\sim 20 \%$ the relative humidity $(\mathrm{RH})$. Measurements began on dry samples. When the weights reached a constant value for several days (samples weighed daily) it was assumed that equilibrium was established. When a stable weight was achieved, the RH was increased and the process repeated at the same temperature. The maximum saturations achieved at the highest RH ( $98 \%)$ were $\sim 25 \%$. A balance with a sensitivity of $0.01 \mathrm{mg}$ calibrated to a traceable standard was used to weigh the samples. Saturation is calculated by comparing weights with dry weights and taking into account porosity. The process was then repeated for the drying portion of the measurement. This cycle of measurement was then repeated at a different temperature.

To investigate the effect of temperature on subsequent measurements, measurements were performed at room temperature on twelve samples of similar porosity. This group was then subdivided into several groups, each having similar moisture retention curves at $24.8^{\circ} \mathrm{C}$. The moisture retention curve of a sub-group of three samples was measured at $93.6^{\circ} \mathrm{C}$. Upon completion of the cycle, two samples from the main group were added to the first sub-group. Measurements were then initiated at $78.4^{\circ} \mathrm{C}$, as previously described. At each subsequent lower temperature measurement, two samples from the main group (that have not been subjected to elevated temperatures) will be added to the sub-group. One difficulty was the establishment of 
steady weight values at the highest humidities, particularly at $93.6^{\circ} \mathrm{C}$. The reason for this difficulty is the $\mathrm{RH}$ is difficult to control at the highest settings and the weight of the samples is more sensitive to changes in RH at the highest settings. Refinement of the control parameters on the humidity chambers aided in the solution of this problem.

\section{Measurement Uncertainty}

The uncertainties involved in the determination of the moisture retention curves include the measurements of weights, relative humidity and sample size. The sample dimensions are used to determine sample wet and dry densities. It is estimated that the thickness of the sample can be determined to $\pm 0.005 \mathrm{~mm}$ and diameter to $\pm 0.05 \mathrm{~mm}$. For the samples used here, this results in an error in sample volume of $\sim \pm 0.3 \%$. The uncertainty in dry weight is estimated to be $\sim 0.00002 \mathrm{~g}$ and for wet weight $\sim 0.0001 \mathrm{~g}$. The error in the wet weight is higher than that of the dry condition because of the difficulty in achieving and maintaining saturation levels of $100 \%$. These uncertainties result in errors in dry and wet densities of $\sim 0.3 \%$. When propagated through to porosity, the error is $\sim 1.0 \%$ porosity, or $\sim 7-11 \%$ of the measurement (Bevington and Robinson, 1992). For example, sample USW-G4 wafer 1 has a porosity of $9.29 \pm 1.09 \%$.

When repetitive measurements are made on samples over a period of several days, such as the determination of weights at a specified relative humidity, for example, the uncertainty in the measurement is often less than the statistical uncertainty in the mean of the measured parameter. In such cases the error is taken as one standard deviation of the mean. The errors in saturation determined at specific temperature and $\mathrm{RH}$ vary from $\sim 0.07$ to $0.5 \% \mathrm{Sw}$. Thus, the relative uncertainty is between $\sim 1$ and $10 \%$, with a $1-2 \%$ error most common.

The uncertainty in the relative humidity is approximately $\pm 2 \% \mathrm{RH}$. When propagated through equation 1 to matric potential, the absolute uncertainties are fairly low, but the relative uncertainties are high at the matric potentials closest to zero (as much as $200 \%$ at $\psi=-1.36 \pm 2.73 \mathrm{MPa}$ ).

\section{Results and Discussion}

USW-G4. Moisture retention curves at $24.8^{\circ} \mathrm{C}$ (wetting and drying) and $93.6^{\circ} \mathrm{C}$ (wetting only) were reported by Roberts and Lin (1995). The additional data reported here include the drying 
curve at $93.6^{\circ} \mathrm{C}$ and the wetting/drying curves at $78.4^{\circ} \mathrm{C}$. Figures $1 \mathrm{a}$ and $1 \mathrm{~b}$ are plots of saturation as a function of matric potential at $24.8^{\circ} \mathrm{C}$ for wetting and drying. All the data points (12 samples) are plotted to demonstrate the heterogeneity of the material and hence the range of values obtained. The line through the data points is the average of all 12 samples. The dashed line shows the expected trend of the data at higher saturations. Hysteresis was observed between the wetting and drying curves, with the drying curve slightly more saturated at any one $\psi$ than the wetting curve.
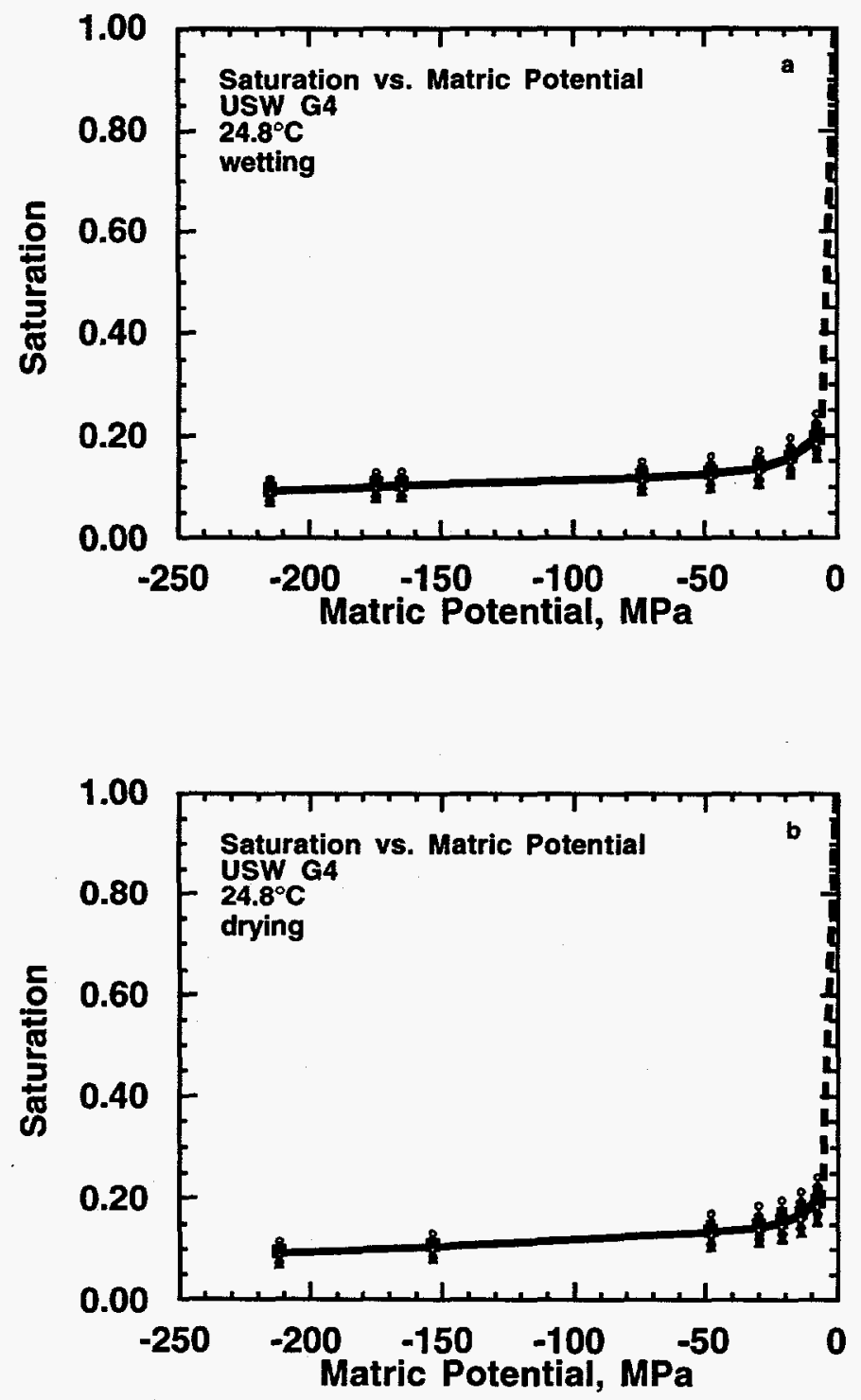

Figure 1. Saturation versus matric potential for $12 \mathrm{USW}-\mathrm{G} 4$ samples at $24.8^{\circ} \mathrm{C}$. Solid line indicates the average for all samples. Dashed line indicates the expected trend. a). Wetting curve. b). Drying curve. 
At $93.6^{\circ} \mathrm{C}$, the moisture retention curve was determined for three samples, 2,4 , and 11 . These results are shown in Figure 2. The data at these temperatures display a much higher degree of scatter than the data obtained at 24.8 and $78.4^{\circ} \mathrm{C}$, particularly at the highest relative humidities. One reason for this is that it was difficult to obtain stable weights for the sample under these conditions. In spite of these difficulties, a significant difference exists between the $93.6^{\circ} \mathrm{C}$ data and the data at $24.8^{\circ} \mathrm{C}$, and that is the wetting curve is higher in saturation than the drying curve. Hysteresis is still observed, but the curves are reversed with respect to saturation. The reason for this occurrence is not understood at this time. On a sample by sample examination, it appears that this is true for each sample.

The next measurements were performed at $78.4^{\circ} \mathrm{C}$. In addition to samples 2,4 , and 11 , measurements were made on samples 9 and 12 . The two samples were included in an attempt to determine whether or not previous heating had an effect on the moisture retention curves. Figure 3 shows the average saturation for five samples versus matric potential. An important observation is that for the $78.4^{\circ} \mathrm{C}$ data, very little hysteresis is observed (less hysteresis than that displayed by the $24.8^{\circ} \mathrm{C}$ data), and the data display much less scatter than the $93.6^{\circ} \mathrm{C}$ data.

Direct comparison of the moisture retention curves at different temperatures is shown in Figure 4. This figure shows that the saturation at any given matric potential decreases as temperature increases, with the exception of the $93.6^{\circ} \mathrm{C}$ wetting curve (vide supra). Stated in a different way, this indicates that the matric potential at a given saturation is the least (nearest to zero potential) at higher temperatures. 


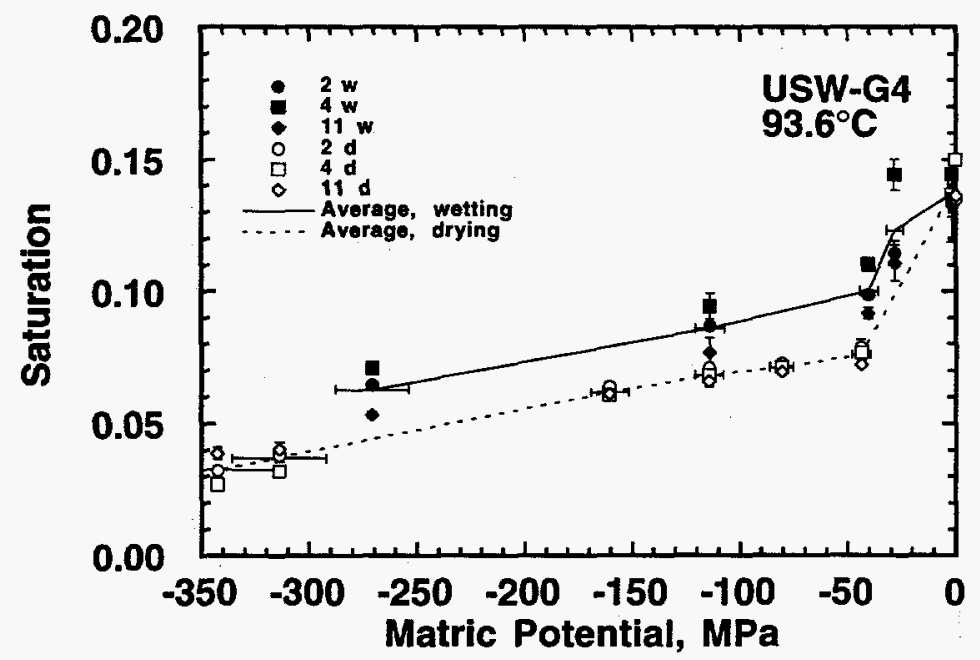

Figure 2. Saturation versus matric potential at $93.6^{\circ} \mathrm{C}$. Closed symbols represent wetting and open symbols drying. The averages for the three samples are shown as the solid line (wetting) and dashed line (drying).

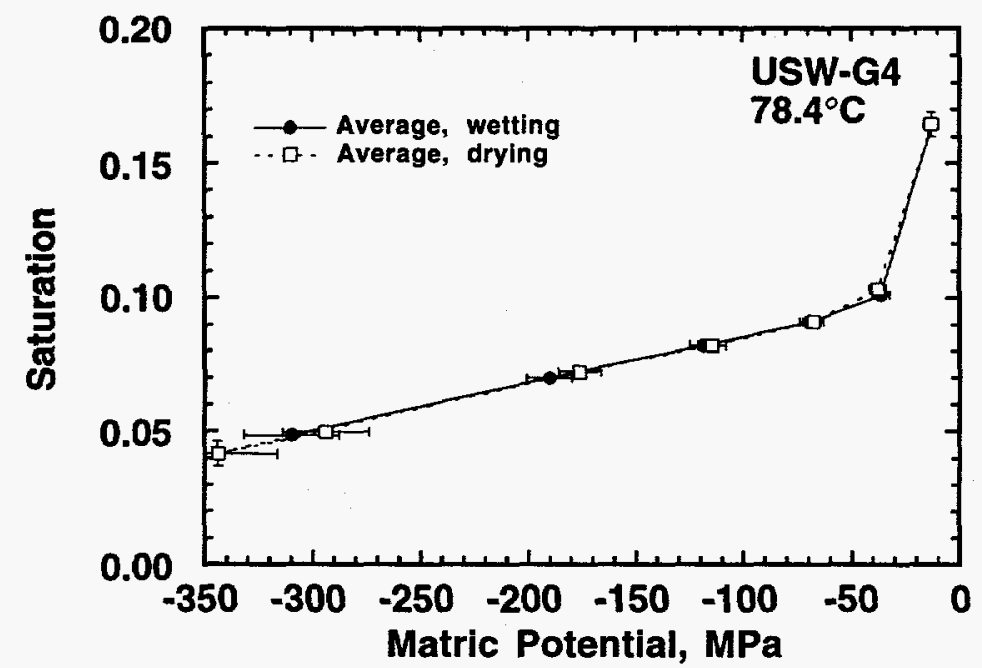

Figure 3. Saturation as a function of matric potential at $78.4^{\circ} \mathrm{C}$ for five samples. Filled symbols represent wetting and open symbols represent drying. Note the lack of hysteresis. 


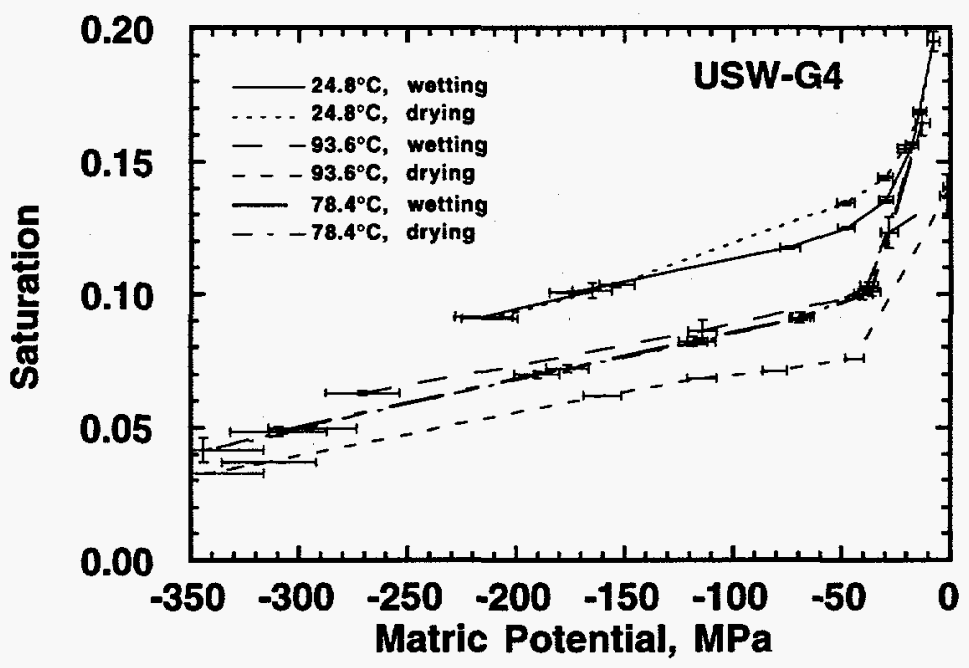

Figure 4. Average moisture retention curves at $24.8,93.6$, and $78.4^{\circ} \mathrm{C}$.

Large Block Test Samples. Thirty-six samples from the Large Block have been prepared. The samples were taken from recovered core from boreholes within the block. At present, the dry and saturated weights have been determined, and from these parameters the dry densities, wet densities and porosities have been calculated. These data are summarized in Table 1.

\section{Future work}

Measurements on the samples from USW-G4 will continue. The samples are currently in the wetting phase of a saturation/de-saturation cycle at $50^{\circ} \mathrm{C}$. Two samples were added to the group of samples at $50^{\circ} \mathrm{C}$ that had not yet been subjected to high temperatures in the laboratory. One additional experiment to be performed with these samples is to begin the drying portion of the experiment with completely saturated samples. The LBT samples are prepared and ready for measurement. Measurements will begin upon the availability of a humidity chamber. 
Acknowledgments. Dave Ruddle and Ron Pletcher provided technical support. Brett Econimedes helped with data reduction. This work was supported by the Yucca Mountain Site Characterization Project. Work performed under the auspices of the US. Department of Energy by Lawrence Livermore National Laboratory under contract W-7405-ENG-48.

\section{References}

Bevington, P. R., and D. K. Robinson, Data reduction and error analysis for the physical sciences, 2nd ed., McGraw-Hill, San Francisco, 328p, 1992.

Marshall, T. J., and J. W. Holmes, Soil physics, 2nd ed., Cambridge University Press, Cambridge, 374p., 1992.

Roberts, J. J., and W. Lin, Hydrological property measurements of Topopah Spring Tuff, Rep. UCRL-ID-119033, Lawrence Livermore Natl. Lab., Calif., 1995. 
Table 1. Large Block Test samples prepared for moisture retention experiments.

\begin{tabular}{|c|c|c|c|c|c|c|c|}
\hline Sample ${ }^{\dagger}$ & Sample ID & Depth, $\mathrm{m}$ & dry wt, $g$ & wet wt, $\mathrm{g}$ & $\begin{array}{c}\text { dry density, } \\
\mathrm{g} / \mathrm{cm}^{3} \\
\end{array}$ & $\begin{array}{c}\text { wet density, } \\
\mathrm{g} / \mathrm{cm}^{3}\end{array}$ & porosity \\
\hline N1-6.3 & 0032079.3 & 1.92 & 1.5352 & 1.6111 & 2.23 & 2.35 & 0.110 \\
\hline $\mathrm{N} 1-6.3 \mathrm{~A}$ & $0032079.3 \mathrm{~A}$ & 1.92 & 1.7890 & 1.8680 & 2.26 & 2.36 & 0.0997 \\
\hline $\mathrm{N} 1-6.3 \mathrm{~B}$ & $0032079.3 B$ & 1.92 & 1.6358 & 1.7098 & 2.28 & 2.39 & 0.103 \\
\hline $\mathrm{N} 1-11.0$ & 0032081.3 & 3.35 & 1.6352 & 1.7181 & 2.25 & 2.37 & 0.114 \\
\hline $\mathrm{N} 1-11.0 \mathrm{~A}$ & $0032081.3 \mathrm{~A}$ & 3.35 & 1.5920 & 1.6734 & 2.26 & 2.38 & 0.116 \\
\hline $\mathrm{N} 1-11.0 \mathrm{~B}$ & $0032081.3 \mathrm{~B}$ & 3.35 & 1.6762 & 1.7525 & 2.30 & 2.41 & 0.105 \\
\hline $\mathrm{N} 1-13.45$ & 0032082.3 & 4.10 & 1.4982 & 1.5752 & 2.27 & 2.39 & 0.117 \\
\hline $\mathrm{N} 1-13.45 \mathrm{~A}$ & $0032082.3 \mathrm{~A}$ & 4.10 & 1.7118 & 1.7951 & 2.27 & 2.38 & 0.110 \\
\hline N1-13.45B & $0032082.3 \mathrm{~B}$ & 4.10 & 1.6954 & 1.7781 & 2.26 & 2.37 & 0.110 \\
\hline N1-16.9 & 0032083.3 & 5.15 & 1.6499 & 1.7522 & 2.20 & 2.33 & 0.136 \\
\hline N1-16.9A & $0032083.3 \mathrm{~A}$ & 5.15 & 1.6094 & 1.6987 & 2.23 & 2.35 & 0.124 \\
\hline N1-16.9B & $0032083.3 \mathrm{~B}$ & 5.15 & 1.6885 & 1.7670 & 2.27 & 2.38 & 0.106 \\
\hline $\mathrm{N} 1-20.3$ & 0032084.3 & 6.19 & 1.5438 & 1.6133 & 2.22 & 2.32 & 0.0998 \\
\hline N1-20.3A & $0032084.3 \mathrm{~A}$ & 6.19 & 1.5567 & 1.6244 & 2.26 & .2 .36 & 0.0982 \\
\hline $\mathrm{N} 1-20.3 \mathrm{~B}$ & $0032084.3 \mathrm{~B}$ & 6.19 & 1.5109 & 1.5849 & 2.21 & 2.32 & 0.108 \\
\hline N4-11.6 & 0032104.3 & 3.54 & 1.5429 & 1.6036 & 2.26 & 2.34 & 0.0887 \\
\hline $\mathrm{N} 4-11.6 \mathrm{~A}$ & $0032104.3 \mathrm{~A}$ & 3.54 & 1.6222 & 1.6864 & 2.24 & 2.33 & 0.0886 \\
\hline N4-11.6B & $0032104.3 B$ & 3.54 & 1.6375 & 1.6969 & 2.27 & 2.35 & 0.0823 \\
\hline N5-4.9 & 0032107.3 & 1.49 & 1.6998 & 1.7687 & 2.25 & 2.34 & 0.0911 \\
\hline N5-4.9A & $0032107.3 \mathrm{~A}$ & 1.49 & 1.6501 & 1.7104 & 2.28 & 2.37 & 0.0834 \\
\hline N5-4.9B & $0032107.3 \mathrm{~B}$ & 1.49 & 1.8818 & 1.9569 & 2.31 & 2.40 & 0.0922 \\
\hline N5-20.4 & 0032111.3 & 6.22 & 1.5230 & 1.5909 & 2.22 & 2.32 & 0.0992 \\
\hline N5-20.4A & $0032111.3 \mathrm{~A}$ & 6.22 & 1.4883 & 1.5593 & 2.21 & 2.32 & 0.106 \\
\hline N5-20.4B & $0032111.3 \mathrm{~B}$ & 6.22 & 1.4765 & 1.5463 & 2.22 & 2.32 & 0.105 \\
\hline N6-4.75 & 0032112.3 & 1.43 & 1.7549 & 1.8228 & 2.25 & 2.33 & 0.0869 \\
\hline N6-4.75A & $0032112.3 \mathrm{~A}$ & 1.43 & 1.6761 & 1.7374 & 2.29 & 2.37 & 0.0837 \\
\hline N6-4.75B & $0032112.3 \mathrm{~B}$ & 1.43 & 1.7136 & 1.7755 & 2.27 & 2.35 & 0.0819 \\
\hline N6-14.2 & 0032116.3 & 4.33 & 1.6590 & 1.7398 & 2.26 & 2.37 & 0.110 \\
\hline N6-14.2A & $0032116.3 \mathrm{~A}$ & 4.33 & 1.6869 & 1.7706 & 2.24 & 2.35 & 0.111 \\
\hline N6-14.2B & $0032116.3 \mathrm{~B}$ & 4.33 & 1.6285 & 1.7137 & 2.23 & 2.35 & 0.117 \\
\hline N7-5.7 & 0032120.3 & 1.74 & 1.6161 & 1.7003 & 2.24 & 2.36 & 0.117 \\
\hline N7-5.7A & $0032120.3 \mathrm{~A}$ & 1.74 & 1.6320 & 1.7051 & 2.29 & 2.39 & 0.102 \\
\hline N7-5.7B & $0032120.3 \mathrm{~B}$ & 1.74 & 1.7091 & 1.7834 & 2.28 & 2.38 & 0.0991 \\
\hline $\mathrm{N} 7-11.0$ & 0032123.3 & 3.35 & 1.5850 & 1.6705 & 2.25 & 2.37 & 0.121 \\
\hline $\mathrm{N} 7-11.0 \mathrm{~A}$ & $0032123.3 \mathrm{~A}$ & 3.35 & 1.6353 & 1.7171 & 2.26 & 2.38 & 0.113 \\
\hline N7-11.0B & $0032123.3 \mathrm{~B}$ & 3.35 & 1.6318 & 1.7112 & 2.27 & 2.38 & 0.110 \\
\hline mean* & 36 samples & & & & $2.25 \pm 0.03$ & $2.36 \pm 0.02$ & $0.104 \pm 0.013$ \\
\hline
\end{tabular}

† Sample name consists of borehole designation followed by depth in feet below the template used to locate vertical boreholes.

*Statistical mean for 36 samples. Errors represent one standard deviation for all samples collectively. 
the ADD achieved from a circular blank can be made as a function of anisotropy and yield criterion assumption, and the results of this are shown in the bar graphs of Fig. 10a-b. For this cupping operation, we use a $100 \mathrm{~mm}$ punch with a $200 \mathrm{~mm}$ blank for a draw ratio of 2.0 . Thus, in addition to the earing effect, the adjusted draw depth $A D D$ will be affected by the LDR that would be predicted due to each of the yield criteria. This is shown immediately in Flg. 10a even for the $\Delta R=0$ case, where 48 Hill predicts a much higher ADD due to the fact that an average value of $\bar{R}=2.1$ is used. In spite of this, the highest ADD is predicted by the 79 Hosford criterion for $\Delta A>0$, as the 48 Hill criterion predicts a much higher earing percent which is detrimental with the use of a round blank. Note though that the 89 Barlat predicts nearly as strong a penalty for the $\triangle R>0$ case. For the isotropic case with $\bar{R}=1.0,48$ Hill again predicts a severe reduction in $A D D$, compared to $\bar{R}=2.1$, while both 79 Hosford and 89 Barlat show a much milder reduction. Note that in fact, for the two cases in Fig. 10a with $\Delta R=0$, the 79 Hosford and 89 Barlat criteria should in fact give identical results. We must remember the subtle difference in implementation, however, and the approximation of coincident principal stress and strain for the 79 Hosford case. This may cause some artificial rounding of the comers of the yield surface, effectively lowering the a-value exponent in that sense. This effect, though small, is more noticeable for the $\bar{R}=1.0$ case, which is closer to the LDR and thus experiences more thinning. This may make the 89 Barlat implementation slightly more accurate for cases where $\Delta R=0$ and we are close to the material's forming limit.

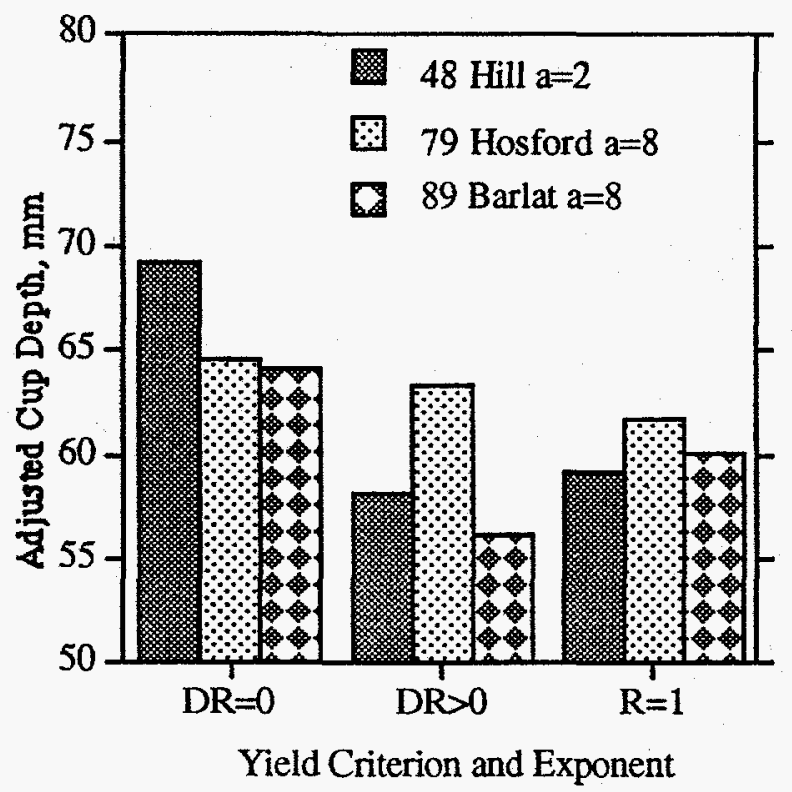

Fig. 10a. Dependence of adjusted draw depth (ADD) on assumptions of anisotropy and yield criterion; effect of yield criterion compared.

Fig. 10b rearranges the data above in a way to show the sensitivity of each criterion to the assumed anisotropy. As expected, 48 Hill shows a strong reduction in ADD due to either the $\Delta R>0$ or $\bar{R}=1.0$ assumption, while the 79 Hosford is rather insensitive to either. The 89 Barlat is most sensitive to the $\Delta R>0$ condition, consistent with the observations above.

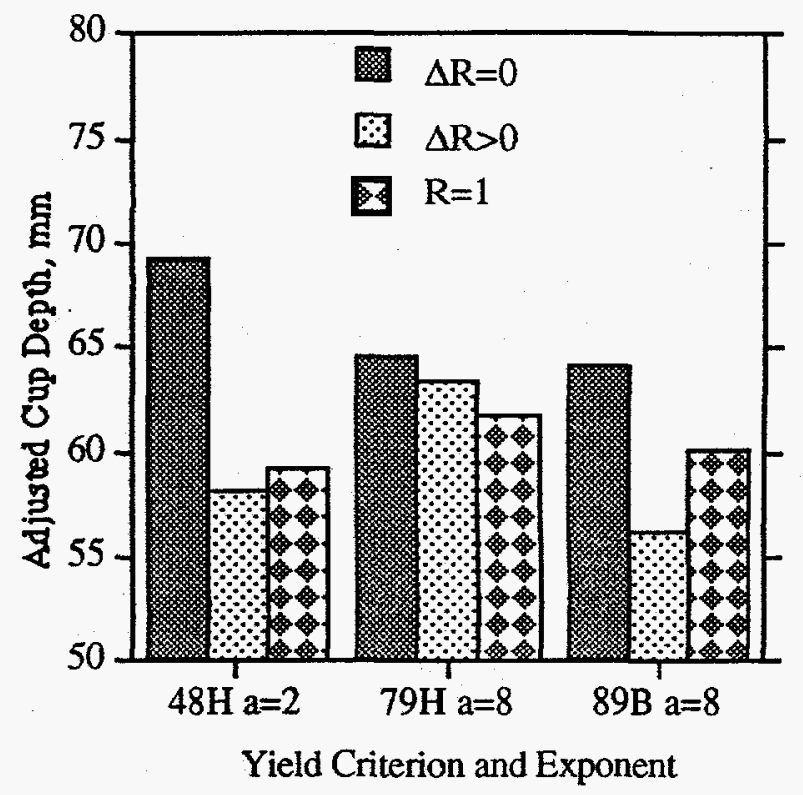

Fig. 10b. Dependence of adjusted draw depth (ADD) on assumptions of anisotropy and yield criterion; effect of anisotropy compared.

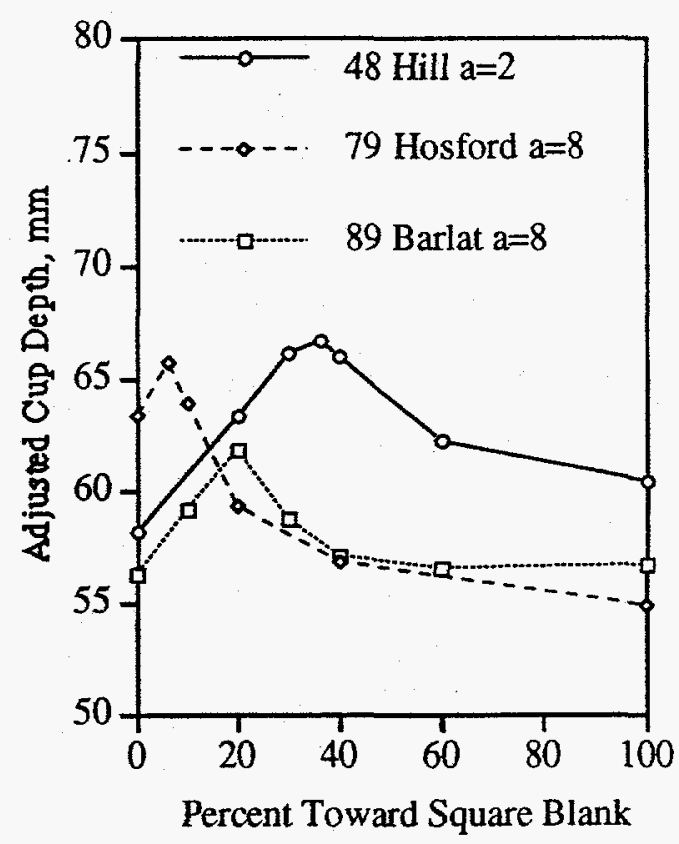

Fig. 11. Determination of optimum blank shape (PTS) for the forming of cylindrical cups from D38 uranium with planar anisotropy; effect of yield criterion.

Fig. 11 shows the effect of assumed yield criterion on the blank optimization effort which is only meaningful for $\Delta R>0$; the case for $\Delta R<0$ is obviously symmetric. All of the criteria show a strong dependence of ADD on PTS as the optimum PTS is approached, 
with the 48 Hill showing PTS $=36$ as the greatest deviation from a circular blank. The optimum for the 79 Hosford criterion is, as expected, the closest to a circular blank at PTS $=6$. The 89 Barlat optimum is as might be expected between the two others at PTS $=20$, but with a much lower value of ADD at the optimum, due to its unique prediction of a high dependence of earing due to $\Delta R=1.4$ but only a small increase in LDR due to $\bar{R}=2.1$

\section{SUMMARY AND FUTURE WORK}

Using full 3D finite-element simulations of the cupping process for cylindrical and square cups, the features of the 1979 Hosford and 1989 Barlat 'TriComponent' yield surfaces are examined as compared to the 1948 Hill tendencies to overpredict LDR and earing effects. The 89 Barlat seems to give results intermediate between the two others for earing phenomena, and agrees (in principle) exactly with 79 Hosford for normal anisotropy. In fact, a slight difference is observed which may be due to more accurate reproduction of the yield surface comers in the 89 Barlat implementation. For the case of earing in general and specifically with the D38 uranium examined here and in ref. [11], additional yield criteria such as the 6-component model of Barlat et al. [17] or other may be desired in the future.

\section{ACKNOWLEDGMENTS}

The author wishes to thank A.J. Sunwoo and D.H. Wood of LLNL for helpful discussions on the warm forming of uranium. This work was performed under the auspices of the U.S. Department of Energy by the Lawrence Livermore National Laboratory under contract W-7405-Eng-48.

\section{REFERENCES}

1. Wilson, D.V. and Butler, R.D., "The Role of CupDrawing Tests in Measuring Drawability", J. Inst. Metals 90, (1962) p. 473.

2. Logan, R.W., Meuleman, D.J., and Hosford, W.F., "The Effects of Anisotropy on the Limiting Drawing Ratio", in Formability and Metallurgical Structure, eds. A.K. Sachdev and J.D. Embury, TMS-AIME, (1987) p.159.

3. Yang, D.Y. and Kim, Y.J., "A Rigid-Plastic FiniteElement Formulation for the Analysis of General Deformation of Planar Anisotropic Sheet Metals and its Applications", Int. J. Mech. Sci. 28, No. 12, (1986) p. 825-840.

4. Logan, R.W., "Finite-Element Analysis of Earing Using Non-Quadratic Yield Surfaces", in NUMIFORM 95 Proceedings, June 18-21, Ithaca, NY, ed. S.F. Shen and P.R. Dawson, Balkema publishers, Rotterdarn, (1995) p.755.

5. Hayashida, Y., Maeda, Y., Matsui, K., Hashimoto, N., Hattori, S., Yanagawa, M., Chung, K., Barlat, F., Brem, J.C., Lege, D.J., and Murtha, S.J., "FEM analysis of punch stretching and cup drawing tests for aluminum alloys using a planar anisotropic yield function", in NUMIFORM 95 Proceedings, June 18-21, Ithaca, NY, ed. S.F. Shen and P.R. Dawson, Balkema publishers, Rotterdam, (1995) p.717.

6. Hill, R., The Mathematical Theory of Plasticity, Clarendon Press, Oxford (1948).
7. Hosford, W.F., "On Yield Loci of Anisotropic Cubic Metals", Proc. 7th N. Amer. Metal Working Research Conf., SME, Dearbom (1979) p. 191.

8. Whirley, R.G., and Hallquist, J.O., "DYNA3D: A Nonlinear, Explicit, Three-Dimensional Finite Element Code for Solid and Structural Mechanics- User Manual," University of California, Lawrence Livermore National Laboratory, Report UCRL-MA-107254 (1991).

9. Barlat, F. and Lian, J., "Plastic Behavior and Stretchability of Sheet Metals, Part I: A Yield Function for Orthotropic Sheets Under Plane Stress Conditions", Int. J. Plasticity 5, (1989) pp. 51-66.

10. Kobayashi, S., Oh, S.I., and Altan, T., Metal Forming and the Finite-Element Method, Oxford Univ. Press, New York. (1979).

11. Hughes, A.N., Lane, R.A., and Orman, S., "The Effects of Warm Work on Some Mechanical and Fabrication Properties of Uranium", J. Nuclear Materials 48 (1973) p. 172.

12. Maker, B.N., "NIKE3D, A Nonlinear, Implicit, ThreeDimensional Finite Element Code for Solid and Structural Mechanics - User's Manual", UCRL-MA-105268, (1991).

13. Whirley, R.G., Engelmann, B.E., and Logan , R.W., "Some Aspects of Sheet Forming Simulation Using Explicit Finite Element Techniques", CED-Vol. 5, AMD Vol. 156, "Numerical Methods for Simulation of Industrial Metal Forming Processes", ed. M.J. Saran, A.B. Pifko, N. Kikuchi, and K.K. Tamma, ASME (1992).

14. Logan, R.W., and Hosford, W.F., "Upper-Bound Anisotropic Yield Locus Calculations Assuming [111] Pencil Glide", Int. J. Mechanical Sci. 22, (1980) p.419.

15. Krieg, R.D. and Key, S.W., "Implementation of a Time Dependent Plasticity Theory into Structural Computer Programs", Vol. 20 of Constitutive Equations in Viscoplasticity: Computational and Engineering Aspects, ASME, New York, NY, (1976) p.125.

16. Bathe, K.J., Finite Element Procedures in Engineering Analysis, Prentice-Hall, Englewood Cliffs, N.J. (1982).

17. Barlat, F., Chung, K., Shah, K.N., Lege, D.J. and Brem, J.C., "Modeling Sheet Forming of Polycrystalline Metals", 2nd World Congress on Computational Mech., Stuttgart, Germany, Aug. 27-31, (1990) p. 383. 